Research Article

\title{
EMI Technique for Monitoring the Damage Evolution of Initial Damaged Tunnel Invert Concrete Subjected to High Traffic Cyclic Loading
}

\author{
Yichao Ye $\mathbb{D},{ }^{1}$ Limin Peng, ${ }^{1}$ Yuexiang Lin $\mathbb{D},{ }^{2}$ Jianwen Liu $\mathbb{D},{ }^{1}$ Mingfeng Lei $\mathbb{D},{ }^{1}$ \\ and Ruizhen Fei $\mathbb{D}^{1}$ \\ ${ }^{1}$ School of Civil Engineering, Central South University, 22 Shaoshan Road, Changsha 410075, China \\ ${ }^{2}$ School of Aeronautics and Astronautics, Sun Yat-sen University, Shenzhen 518107, China \\ Correspondence should be addressed to Yuexiang Lin; csulyx2010@csu.edu.cn and Jianwen Liu; jwenliu@csu.edu.cn
}

Received 18 October 2019; Revised 27 July 2020; Accepted 11 October 2020; Published 29 October 2020

Academic Editor: Wayne Yu Wang

Copyright (c) 2020 Yichao Ye et al. This is an open access article distributed under the Creative Commons Attribution License, which permits unrestricted use, distribution, and reproduction in any medium, provided the original work is properly cited.

\begin{abstract}
The electromechanical impedance (EMI) technique based on the PZT transducer, in the past twenty years of research progress, has demonstrated its potential for cost-effective and high damage-sensitive structural health monitoring. This paper presents an application of EMI technique for damage evolution investigation of initial damaged tunnel invert concrete under high traffic cyclic loading. In the tests, six different levels of initial damage inside the specimens, as the influencing factor, were firstly created by applying a certain number of impacts with a free-falling iron ball. Then, these specimens were applied typical mechanical boundaries similar to that of tunnel invert concrete by an installation specially designed. Finally, the traffic cyclic loading carefully determined was exerted by the MTS815 hydraulic zero-control testing system, to investigate the evolution characteristic of piezoelectric signature of the PZT sensor. The experimental result shows that the conductance signature follows a consistent rightward shifting with the number of cycles increasing, and the larger the initial damage of the specimen, the more obvious the rightward shifting. It indicates that, in general, the traffic cyclic loading is not large enough to make the microcracks propagate to fatigue failure in tunnel invert concrete even if there is a large initial damage. On the contrary, with special mechanical boundaries, the local nominal stiffness of tunnel invert concrete will gradually increase. This phenomenon may be interpreted as an effect of generalized damage recovery. A new damage index, with values between 0 and 1 , was then defined to quantify the damage level for quantitative analysis. It was found that the damage recovery behaviors for different initial damaged specimens can be well and uniformly described by an empirical expression, which may be helpful for the damage assessment of tunnel invert concrete under high traffic cyclic loading in the future.
\end{abstract}

\section{Introduction}

To date, it has formed a consensus that concrete can be regarded as an electrochemical system composed of porous media, and changes of microstructures in concrete can cause changes of mechanical impedance [1]. It is encouraging that the electromechanical coupling property of piezoelectric materials such as PZT makes it possible to measure the mechanical impedance of the monitored concrete structure. In addition, owing to a high frequency of excitation, the PZT materials have very high sensitivity to damage [2]. Typically, they can be used to detect incipient damage such as microcracks before visible to the naked eyes, and no complex signature processing or any expensive hardware is warranted $[1,3-5]$.

Moreover, a lot of theoretical models have been successfully established to describe the electromechanical coupling relationship between PZT and the host structure, laying a solid foundation for the subsequent applications. For example, Liang et al. $[6,7]$ first proposed an analytical expression to illuminate PZT-structure interaction in 1D structures, predicting its wide prospect of engineering application. Afterwards, $\mathrm{Xu}$ and Liu [8] improved the $1 \mathrm{D}$ model by considering the effect of the bonding layer. 
Following the procedure outlined by Liang et al., Zhou et al. [9] extended the $1 \mathrm{D}$ model to $2 \mathrm{D}$. However, it is limited by the difficulty of extracting the mechanical impedance from experiment. To solve this problem, Bhalla and Soh [4] improved the $2 \mathrm{D}$ model by introducing the concept of "effective impedance," in which the physical properties of the PZT and the host structure in two directions are represented in an impedance value.

Along with the development of theory, experimental implementation for damage detection by EMI technique in concrete structures has been successfully demonstrated by many researchers. Sun et al. [10] first successfully applied the EMI technique for damage detection on an assembled truss structure. Park et al. [11] systematically applied the EMI technique on typical components of civil structures such as composite reinforced-concrete wall, bridge element, and a pipe joint. Soh et al. [5] presented a damage detection study on a prototype RC bridge structure, instrumented with PZT patches. Some other applications in cylindrical shell structures [12], concrete shear wall structures [13], pipelines structures [14], and aircraft [15] also obtained promising results.

In addition, the EMI technique has been proved effective in detecting the damage caused by various external loads like static loads [16-20], impact loads [21-25], cyclic loads [1, 26, 27], and fatigue loads [22, 28-31]. Especially for impact damage and fatigue damage evolution detection that closely related to the topic of this paper, some good findings have been reported, and they are instructive and helpful. For example, Fan et al. [25] simulated the collision damage of a bridge column by using a concrete beam model subjected to continuous impact loadings by a free-falling steel ball. It was observed that the statistical indicator RMSD was linearly increasing with the repeated impact. This conclusion had been validated by Dixit and Bhalla [22] and Qi et al. [24], and it is used to prefabricate the different levels of initial damage of the specimens in this paper. In addition, for the case of damage evolution under fatigue loading, Soh and Lim [30] presented a series of investigative studies to evaluate the feasibility of fatigue crack monitoring and estimation of remaining useful life in 1D lab-sized aluminum beams using the EMI technique. The experimental results indicated that the EMI technique was excellent in detecting incipient microcracks through changes in admittance signature's frequency. Propagation of a crack could also be well reflected from the admittance plot. Afterwards, Lim and Soh [28, 31] proposed that the resonant frequency shifting is closely related to the fatigue crack propagation and life cycles, and the relationship between the resonant frequency reduction and life cycles can be established to estimate the fatigue life. Someone else also used the different damage indexes self-defined, such as RMSD [32, 33], wavelet energy [34], or equivalent damping [22] that are based on PZT admittance signatures in a specific frequency range, to evaluate the fatigue behaviors of host structures. It is meaningful that no matter how the damage index is defined, there is a similar nonlinear relationship between the damage index and the number of cycles. Unfortunately, most of the damage indexes like RMSD are not a bounded indicator (such as between 0 and 1 ), so the damage assessment by them can only be used to make qualitative analysis [25].

Overall, the EMI technique, in the past twenty years of research progress, has demonstrated its potential for costeffective and high damage-sensitive structural health monitoring (SHM) for a wide variety of engineering structures under various loading conditions. However, the majority of applications of EMI technique-related research studies completed to date have focused exclusively on surface structures only; insufficient effort has been made for underground structures like tunnel [35]. The tunnel as a part of the transportation network has dramatically released pressure on the ground transportation system, greatly improved the speed and carrying capacity, and at the same time greatly stimulated the economic growth. The special geometrical configuration and mechanical characteristics make the tunnel stronger than surface structures and less prone to damage from extreme events such as earthquakes, storms, or hurricanes [35]. However, there still exist many problems that need to be fully figured out. One of the critical issues is the influence of high traffic cyclic loading on tunnel invert concrete, which has recently attracted the attention of urban developers worldwide [29]. So far, the dynamic strain history measurements have been evaluated using strain gauges under cyclic loading, where both the structural response and the induced damage are highly erratic [29]. Since the damage accumulating under cyclic loading is usually not visible until substantial loss of strength or stiffness, the EMI technique has a high potential of application here [22].

Thus, this paper addresses major issue related to the damage evolution of impact-induced initial damaged tunnel invert concrete under high traffic cyclic loading. A testing installation is specially designed to apply the mechanical boundaries, simulating the servicing conditions of tunnel invert concrete. Sinusoidal form of cyclic loading that carefully determined is exerted by the MTS815 hydraulic zero-control testing system to simulate the high traffic cyclic loadings. Finally, the MEI technique combined with a new damage index, with values between 0 and 1 , defined based on the root mean square deviation (RMSD) of conductance signature, is used to quantify the damage level and investigate the damage evolution behavior.

\section{The EMI Technique}

The basic concept of EMI technique is to monitor the variations of structural mechanical impedance and/or admittance signatures caused by the onset of damage [36]. The most widely used theoretical model to describe the electromechanical coupling relationship between the PZT transducer and the host structure is the $1 \mathrm{D}$ model that was established by Liang et al. [6, 7]. The electric admittance with respect to frequency is expressed by the following equation:

$$
Y=j \omega \frac{b_{\alpha} l_{\alpha}}{h_{\alpha}}\left(\varepsilon_{33}-\frac{Z_{s}}{Z_{s}+Z_{\alpha}} d_{31}^{2} Y_{11}\right),
$$


where $Z_{s}$ is the mechanical impedance of the host structure and $Z_{a}$ is that of PZT; $l_{a}, b_{a}$, and $h_{a}$ are the length, width, and thickness of PZT, respectively; $\omega$ is the angular frequency; and $\varepsilon_{33}, d_{31}$, and $Y_{11}$ are the material constants of PZT.

Equation (1) predicts the electric admittance across terminals of a PZT surface bonded to any structure [26]. The first term denotes the capacitive admittance of the PZT sensor, corresponding to a baseline that increases with frequency. The second term concisely reflects the electromechanical coupling relationship, which is shown as peaks in the capacitive admittance baseline. If $Z_{a}$ of PZT is assumed to be a constant, the coupling admittance $Y$ of the system is only affected by $Z_{s}$ of the host structure. In other words, any changes happened in the host structure cause change in $Y$.

In practice, the signatures of $\mathrm{PZT}$, such as impedance and admittance, are captured by an impedance analyzer, as illustrated in Figure 1. When the impedance analyzer electrically excited on a PZT patch, the "converse effect" of PZT will produce a coupling vibration of PZT with the host structure. At the same time, the "direct effect" of PZT will transfer this vibration back in the form of admittance (or impedance) signatures, which has contained vital information of the host structure. By certain means of signal processing between the signatures corresponding to the undamaged and damaged states, the damage level of the host structure can be evaluated $[3,5]$.

\section{Experimental Set-Up and Procedure}

3.1. Specimen Preparations. Specimens here are made up of four different concrete mix proportions. The cement used is P.O. 42.5 Portland cement (content of $380 \mathrm{~kg} / \mathrm{m}^{3}$ ) and grade I fly ash (content of $100 \mathrm{~kg} / \mathrm{m}^{3}$ ). The fine aggregate is river sand with the specific gravity of 2.56 , water absorption of $1.4 \%$, and mud content of $0.8 \%$. The coarse aggregate is continuous grading crushed gravel with the maximum size of $20 \mathrm{~mm}$, specific gravity of 2.66 , and mud content of $0.6 \%$. To obtain a slump of $50 \sim 100 \mathrm{~mm}$ for all the concrete mixes, polycarboxylate superplasticizer is added. Table 1 shows the quantities of the constituent materials used in the concrete mixes. Concrete mixes were cast in cube molds with $100 \mathrm{~mm} \times 100 \mathrm{~mm} \times 300 \mathrm{~mm}$ in size. Immediately after they were made in the laboratory, the specimens were covered with plastic sheets to prevent moisture loss and stored for 3 hours at laboratory conditions and then placed in the curing room for 28 days.

Initial damage of concrete is one of the critical factors affecting its load carrying capacity and damage evolution behaviors [37]. It is therefore that the initial damage as the influencing factor was taken into consideration. By applying certain number of impacts on the specimens, different levels of initial damage could be created $[22,24,25]$. In the impact test, the impact loading was simulated by a free-falling iron ball of mass $5 \mathrm{~kg}$ from height of $300 \mathrm{~mm}$ on the specimens. A rectangular steel plate with $100 \mathrm{~mm} \times 100 \mathrm{~mm}$ in size and $10 \mathrm{~mm}$ in thick was rested on the top of the specimen, preventing local damage generated in the impact position. The specimens were rested on a pebble bed so as to avoid second impact. According to the test results, visible cracks could be observed after an average of 30 impacts. Thus, the number of impacts- $0,3,6,9,12,15$-was determined to create six different levels of initial damage inside the specimen.

Then, the damaged specimens prepared for the EMI measurements were each surface bonded with a PZT patch (see Figure 2(d)), which has a diameter of $10 \mathrm{~mm}$ and thickness of $0.5 \mathrm{~mm}$. Key properties of the PZT sensor are given in Table 2. In order to eliminate the influence of temperature, all the tests and measurements were conducted in a temperature of $20^{\circ} \mathrm{C}$, controlled by an air conditioner.

\subsection{Testing System and Mechanical Boundaries of Specimen.} To simulate the mechanical boundaries of tunnel invert concrete, a testing installation that contains a box body, axial force component (AFC), surrounding earth pressure component (SPC) and lateral restraint component (LRC), was designed, as shown in Figures 2(a) 2(c).

Using this installation, the following procedure should be obeyed to apply the mechanical boundaries on the specimen. Firstly, a steel plate with $100 \mathrm{~mm} \times 300 \mathrm{~mm}$ in size and $10 \mathrm{~mm}$ in thick was rested on the top of the specimen, put down the loading head of MTS onto it, and then the surrounding earth pressure was applied by the lifting jack until the target value of $300 \mathrm{kPa}$ (corresponding to a burial depth of $15 \mathrm{~m}$ and bulk density of $20 \mathrm{kN} / \mathrm{m}^{3}$ ) was reached. Secondly, the axial force of $200 \mathrm{kPa}$ was applied by the AFC. Thirdly, the lateral force that was large enough to keep balance with the surrounding earth pressure was applied by the LRC. Finally, raised the loading head of MTS and removed the plate. All these procedures ensured the mechanical boundaries being identical to that of the tunnel invert concrete (see Figure 2(d)) before cyclic loading were applied.

3.3. Determination of Traffic Cyclic Loading. Cyclic loading tests were performed by the MTS 815 hydraulic zero-control testing system using sinusoidal loading. In addition, magnitude of the corresponding static load and dynamic load should be determined firstly. Here, high-speed railway train load, subway train load, and heavy-haul railway train load were taken into consideration. In China, when under full load, the axle weights $\left(P_{\mathrm{aw}}\right)$ of them are usually $170 \mathrm{kN}$, $200 \mathrm{kN}$, and $250 \mathrm{kN}$, respectively. In terms of maximum estimation, assuming that the axle weight of the train passes directly through the railway bogie to tunnel invert concrete, the forced area can be uniformly calculated by the rail gauge $(g)$ times the wheelbase $(w)$. By this way, the static loads $\left(\sigma_{s}\right)$ were estimated, as shown in Table 3.

The dynamic load caused by the running train is related to many factors, such as the running speed, track regularity, 


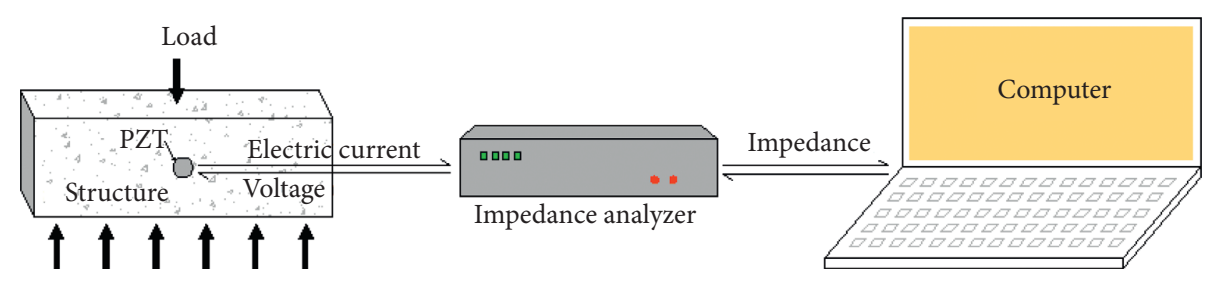

Figure 1: Diagrammatic sketch of the EMI operational process.

TABLE 1: Concrete mix proportions.

\begin{tabular}{lccccc}
\hline Cement content $\left(\mathrm{kg} / \mathrm{m}^{3}\right)$ & Water content $\left(\mathrm{kg} / \mathrm{m}^{3}\right)$ & w/c ratio & fi/c & co/c & Superplasticizer $(\%)$ \\
\hline 480 & 150 & 0.31 & 1.44 & 2.35 & 0.29 \\
\hline
\end{tabular}

axle weight of the train, and so on. The China Academy of Railway Science (CARS) proposed an empirical expression for evaluating the dynamic load of roadbed on the basis of a lot of field tests of DJJ high-speed EMU on GuangzhouShenzhen railway [38]. The empirical expression with respect to axle weight and running speed is expressed as follows:

$$
\sigma_{d}=0.26 \times P \times(1 \pm 0.004 V),
$$

where $\sigma_{d}$ is the dynamic load of roadbed, $\mathrm{kPa} ; P$ is the axle weight of the train, $\mathrm{kN}$; and $V$ is the running speed of the train, $\mathrm{km} / \mathrm{h}$. Using equation (2), the dynamic loads were calculated, and the results are listed in Table 4.

After a comprehensive consideration of the calculated results in Tables 3 and 4, the static load of $200 \mathrm{kPa}$ and the dynamic load of $100 \mathrm{kPa}$ were eventually determined. For efficiency, the sinusoidal cyclic loading applied by MTS was performed at a frequency of $12 \mathrm{~Hz}$ [29], and the number of cycles was set to 1000,000 times.

\section{Results and Discussions}

4.1. Selection of Frequency Range. Before the analysis of test data, there are two critical issues worth to discuss firstly. One is the selection of frequency range, and the other is the definition of damage index (discussed in next Section). For a PZT sensor surface boned to host structure, there are many resonant frequencies that correspond to different vibration modes (see Figure 3(a)). In general, RMSD indexes (equation (3)) calculated from the conductance signatures subjected to a certain resonant frequency are quite different, among which the largest is the one calculated from the conductance signatures subjected to the first resonant frequency (see Figure 3(b)). Some similar observations were also reported by $\mathrm{Ai}$ et al. [19] and Liu et al. [39], indicating that the conductance signature in the first resonant frequency is the most sensitive to damage. An explanation proposed by Liang et al. $[6,7]$ is that the first resonant frequency corresponds to the thickness vibration mode, which fits in with the case of the surface-bonded PZT sensor. In addition, according to the recommendation by Sun et al. [40], the major vibration modes of the structure should be included in the selected signature. In addition, Park et al. [2], Yang et al. [41, 42], and Soh and Bhalla [26] also pointed out that the selected frequency range ought to be less than $400 \mathrm{kHz}$ because at frequencies higher than $500 \mathrm{kHz}$, the PZT patches become sensitive to their own conditions rather than that of the structure they are bonded to. Therefore, using the PV80A impedance analyzer, the EMI spectra of the surface-bonded PZT patches were tracked by sweeping a frequency range between 100 and $300 \mathrm{kHz}$.

4.2. Definition of Damage Index. Reasonable definition of damage index is one of the basic topics of EMI technique in structural damage assessment. Quite often, the root mean square deviation (RMSD) is chosen as the damage index, as expressed in the following equation:

$$
R=\sqrt{\frac{\sum_{i=1}^{n}\left(x_{i}-x_{0, i}\right)^{2}}{\sum_{i=1}^{n} x_{0, i}^{2}}}
$$

where $x_{0, i}$ and $x_{i}(i=1,2,3, \ldots, n)$ represent the initial and damaged admittance (or impedance) signature of the PZTstructure system, respectively, and $R$ represents the RMSD between them.

However, in principle, RMSD as a statistical index only reflects the difference between the signature in the damaged state and that in the initial state, which can be large or small. It is limited by the selection of signatures [43]. For example, RMSD calculated from conductance signature is almost twice as large as that calculated from susceptance signature [25]. In addition, as have been discussed before, the value of RMSD index is also affected by the selection of frequency range [19]. Therefore, the damage level described by RMSD can only be evaluated qualitatively but not quantitatively. 


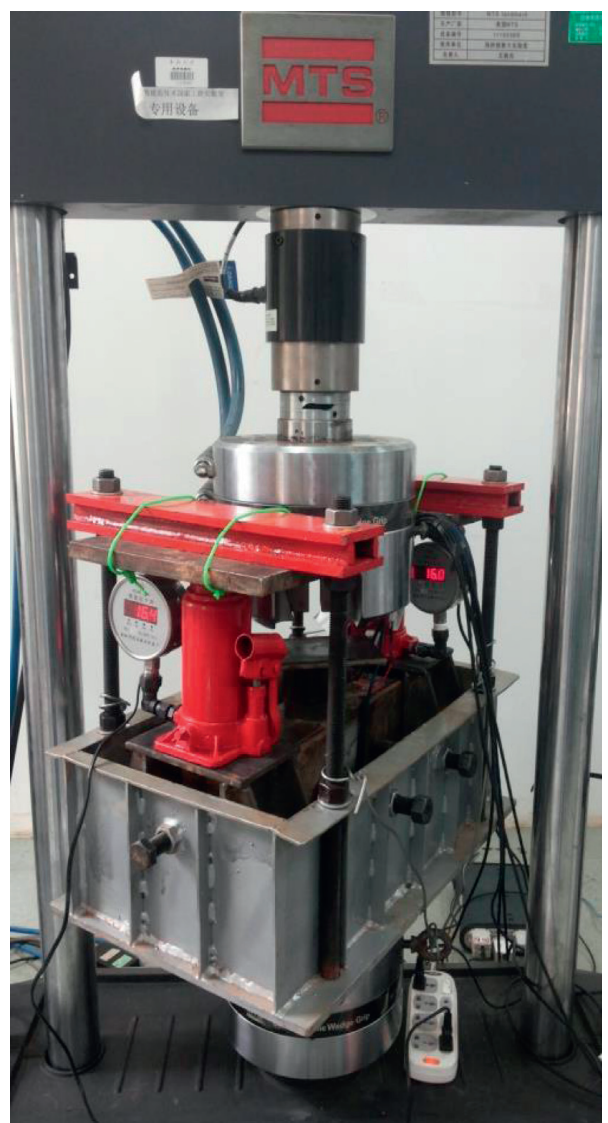

(a)

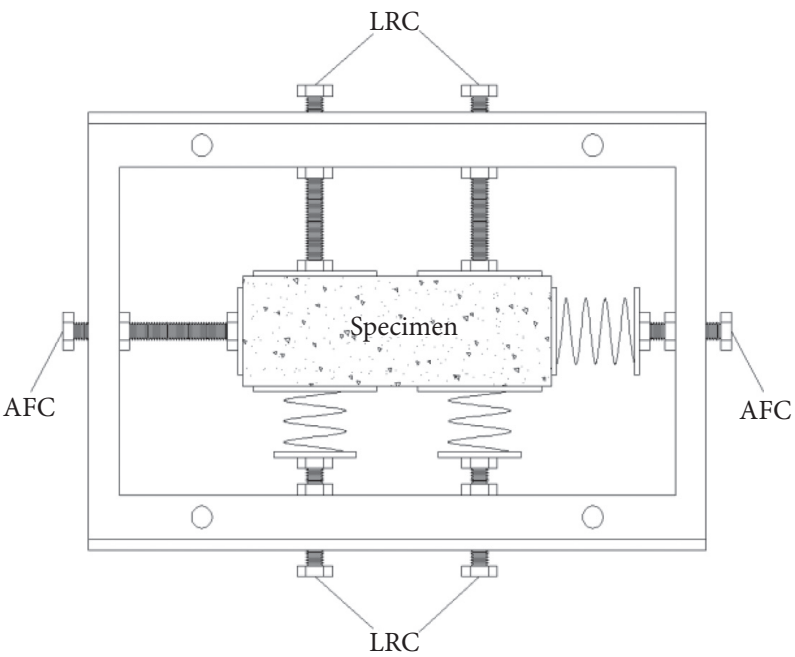

(c)

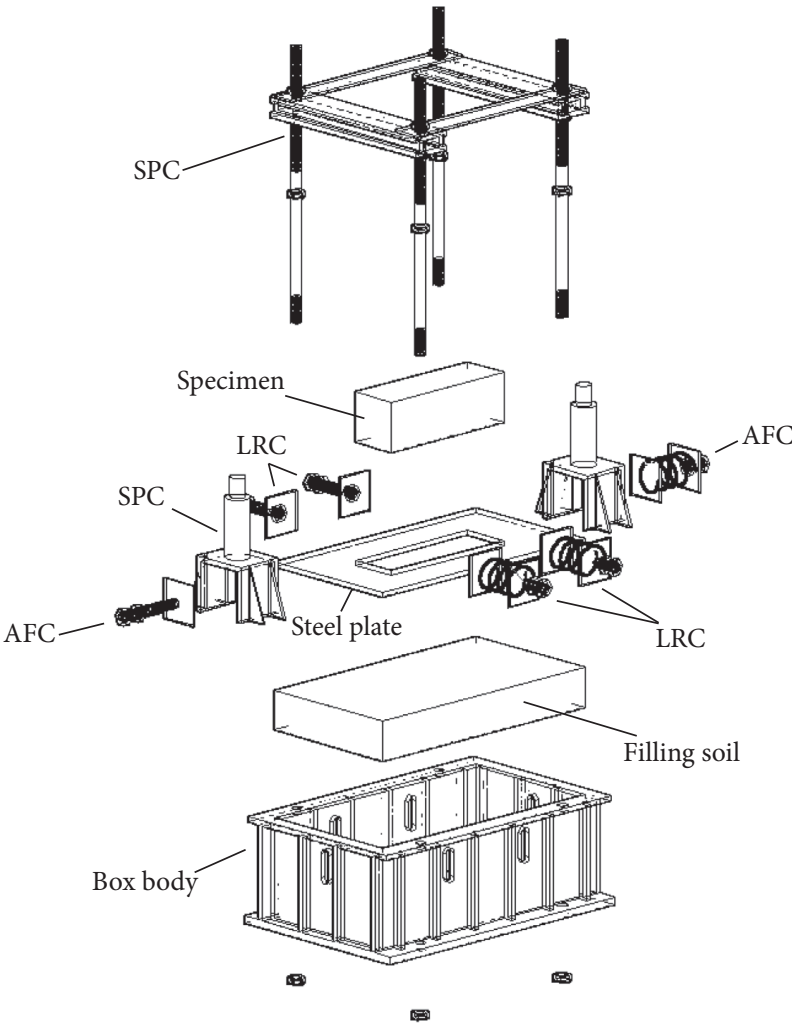

(b)

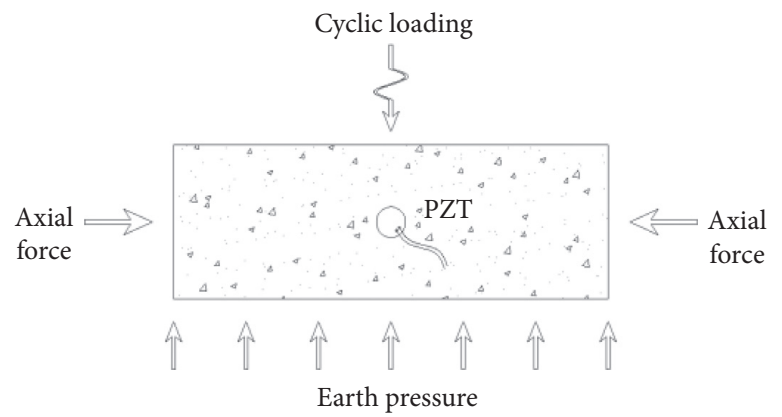

(d)

Figure 2: Schematic diagram of the testing system: (a) overall view; (b) exploded view; (c) top view; (d) side view of specimen's mechanical boundaries and location PZT sensor.

In order to make damage index a bounded indicator, such as $[0,1]$, one can normalize the RMSD values $(R)$ by using the RMSD calculated between the signature acquired at the moment of specimen failure and the signature of initial state $\left(R_{c}\right)$ as the benchmark. The new damage index $D$ can be defined as follows: 
TABLE 2: Key properties of the PZT sensor.

\begin{tabular}{lcc}
\hline Parameter & Symbol & Value \\
\hline Density & $\rho\left(\mathrm{kg} / \mathrm{m}^{3}\right)$ & 7860 \\
Coupling coefficient & $K_{\mathrm{p}}$ & 0.4 \\
Capacitance & $\mathrm{Co}(\mathrm{nF})$ & 4.6 \\
Piezoelectric strain constant & $d_{31}(\mathrm{C} / \mathrm{N})$ & 450 \\
Courier temperature & $C\left({ }^{\circ} \mathrm{C}\right)$ & 260 \\
Mechanical quantity factor & $Q_{\mathrm{m}}$ & 11.8 \\
Dielectric loss factor & $\tan \varphi$ & 0.02 \\
\hline
\end{tabular}

TABle 3: Determination of static load $\sigma_{s}$.

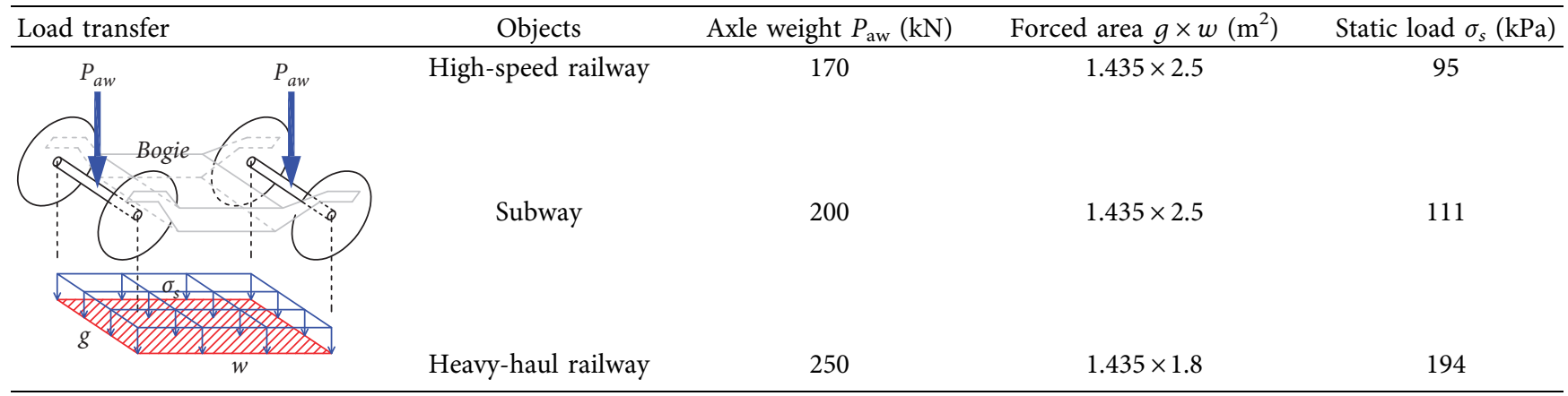

TABLe 4: Determination of dynamic loading $\sigma_{d}$.

\begin{tabular}{lcccc}
\hline Cyclic loading & Objects & Axle weight $P(\mathrm{kN})$ & Speed $V(\mathrm{~km} / \mathrm{h})$ & Dynamic load $\sigma_{d}(\mathrm{kPa})$ \\
\hline$\sigma$ & High-speed railway & 170 & 350 & 106.1 \\
& Subway & 200 & 120 & 77 \\
\hline & & & & \\
& & 250 & 120 & 96.2 \\
\hline
\end{tabular}

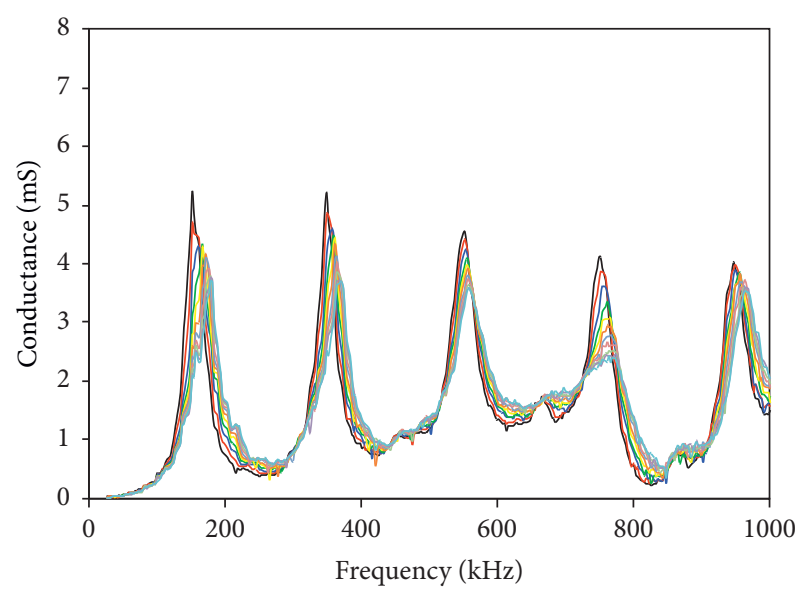

Number of cycles $\mathrm{N}\left(\times 10^{4}\right)$

$\begin{aligned}-0 & -20 \\ 40 & -60 \\ -80 & -100 \\ -10 & -30 \\ 50 & -70 \\ -90 & \end{aligned}$

(a)

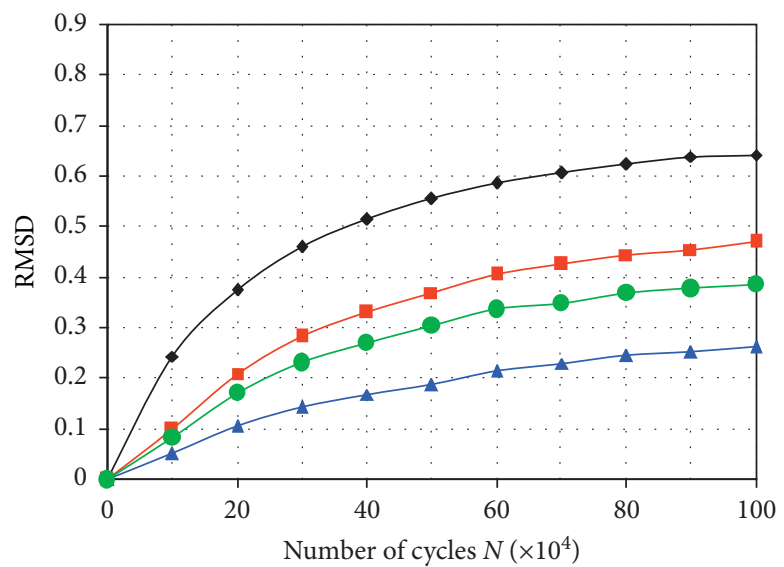

Frequency range

$\rightarrow 100 \sim 300 \mathrm{kHz} \quad \longrightarrow 500 \sim 700 \mathrm{kHz}$

$\rightarrow 300 \sim 500 \mathrm{kHz} \longrightarrow 700 \sim 900 \mathrm{kHz}$

FIGURE 3: The influence of frequency range selection on the damage index: (a) conductance signatures of specimen I15-1; (b) RMSD values calculated from the signatures subjected to a certain resonant frequency range. 


$$
\begin{gathered}
D=\frac{R}{R_{c}}, \\
R_{c}=\sqrt{\frac{\sum_{i=1}^{n}\left(x_{c, i}-x_{0, i}\right)^{2}}{\sum_{i=1}^{n} x_{0, i}^{2}}},
\end{gathered}
$$

where $x_{c, i}(i=1,2,3, \ldots, n)$ is the admittance (or impedance) signature captured at the moment of the PZT-structure system failure.

By substituting equations (3) and (5) into equation (4), it gives that

$$
D=\sqrt{\frac{\sum_{i=1}^{n}\left(x_{i}-x_{0, i}\right)^{2}}{\sum_{i=1}^{n}\left(x_{c, i}-x_{0, i}\right)^{2}}} .
$$

Obviously, $D$ is between 0 and 1 , where $D=0$ means undamaged and $D=1$ means failure. However, in the measurement, the signature of concrete specimen at the moment of failure leaves extremely limited time to be captured. In this case, one may use the free-PZT signature $x_{\text {free }}$ as an alternative to $x_{c}$ (discussed later); accordingly, the damage index defined here can be expressed as

$$
D=\sqrt{\frac{\sum_{i=1}^{n}\left(x_{i}-x_{0, i}\right)^{2}}{\sum_{i=1}^{n}\left(x_{\text {free }, i}-x_{0, i}\right)^{2}}},
$$

where $x_{\text {free }, i}(i=1,2,3, \ldots, n)$ is the signature of free PZT.

Note that the new damage index defined in equation (7) is not only of clear physical significance but also overcomes the problem of signature selection discussed above, as illustrated in Figures 4(c) 4(d) (taking the conductance $G$ and susceptance $B$ signatures of specimen I15-1 for example (see Figures 4(a) 4(b))). Similar observations hold for other specimens. This finding makes more sense for the newly defined damage index because, as we all know, different signatures are supposed to reflect the same damage information of the host structure.

4.3. Quantification of Impact-Induced Initial Damage. Figure 5 shows the conductance signatures obtained from the PZT patch surface bonded on concrete specimens of six different numbers of impacts. In the figures, I0, I3, I6, .. represent the specimens with $0,3,6, \ldots$ number of impacts, respectively; the "free-PZT" signature is that measured at "free state." The "baseline" signature is the average of conductance signatures of specimen I0-1 3 measured at 1000,000 th cycle. Obviously, with the increase in the number of impacts, the curve of conductance signature drives to the left accompanied with increasing amplitude. Geometrically, it gradually approaches to the signature of "free PZT." It is not difficult to understand the trend because the "free state" of PZT can be seen as surface bonded to a completely damaged specimen with no rigidity or strength [25]. Thus, as mentioned in Section 4.2, the signature of free PZT may be a good alternative to that at the failure moment of specimen.
Based on the new damage index defined in equation (7), the average values of initial damages of each set of specimens were quantified, as shown in Figure 6. It was observed that the damage index $D$ was almost linearly increasing with the number of impacts as expected, proving that the impact method is feasible and convenient to prefabricate the initial damage inside the specimen.

4.4. Damage Evolution of Initial Damaged Tunnel Invert Concrete under High Traffic Cyclic Loading. The conductance signatures generated during high cyclic loading were identified, as shown in Figures $7(\mathrm{a}) \sim 7(\mathrm{r})$. In the figures, the number $0,10,20, \ldots, 100$ represents the number of cycles. For example, the number 10 represents the 100,000th cycle, the number 20 represents the 200,000th cycle, and so on.

From Figures $7(\mathrm{a}) \sim 7(\mathrm{c})$, for specimens without being subjected to impact loading (specimen label of I0-1 3), the conductance signatures are found slightly but definitely shifted to the right with number of cycles increasing. As reported in Refs. [26, 44-48], the rightward shifting of conductance signature was observed in the first 30 days of concrete curing process, while in Refs. $[19,20]$, it happens when the compressive stress acting on concrete specimen increases. These findings indicate that the signature rightward shifting with an increase in resonant frequency implies an increase in structural stiffness, which can be interpreted as an effect of generalized damage recovery. So, there is no doubt that the traffic cyclic loading does not increase the damage level of tunnel invert concrete to fatigue failure, no matter how many cycles it has undergone. The only explanation here is that the traffic cyclic loading, even by maximum evaluation, is too small to make the microcracks inside the specimen propagate to fatigue failure. Conversely, the specific mechanical boundaries of tunnel invert concrete lead to the damage form of impactinduced microcracks to some extent closing or interlocking, thereby enhancing the nominal stiffness of specimens. This explanation is supported by the subsequent test results of specimens with larger impact-induced initial damages, in which consistent but larger rightward shifts of conductance signatures were observed (see Figures $7(\mathrm{~d})$ 7(r)).

To describe such an effect of generalized damage recovery, the index defined in equation (7) is also used to quantify the damage level, as shown in Figures 8(a) 8(f). Note that the symbol $D_{r}$ is used to replace symbol $D$ in equation (7) because the plots of conductance signatures shift rightward, so the damage evolution here represents damage recovery rather than damage development.

Regression analysis showed that the damage recovery behaviors using the experimental data in Figure 8 are best fit with exponential function of ExpDec1 of Origin 8.0 in the form of

$$
D_{r}=y_{0}+A_{1} \exp \left(\frac{-N}{t_{1}}\right)
$$



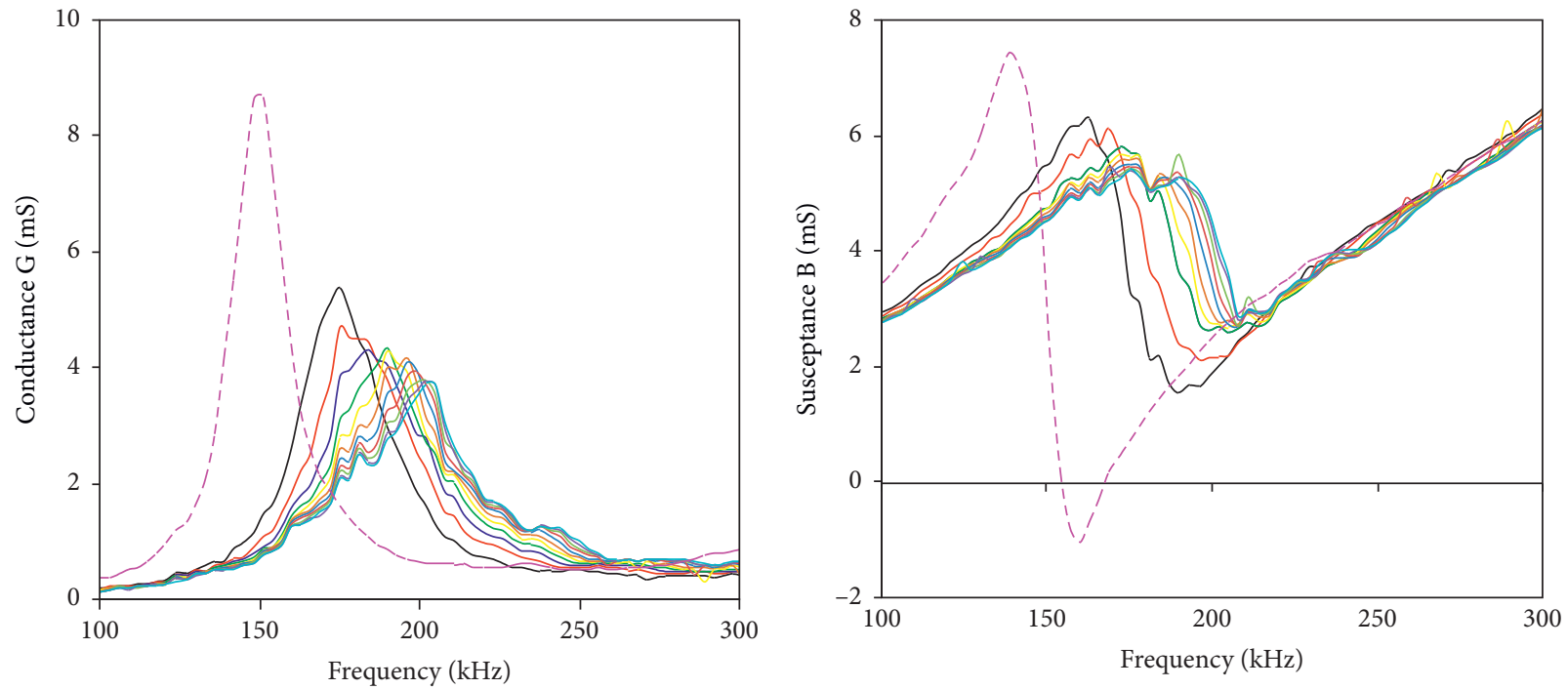

Number of cycles $\left(\times 10^{4}\right)$

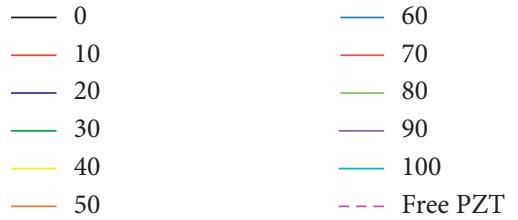

(a)

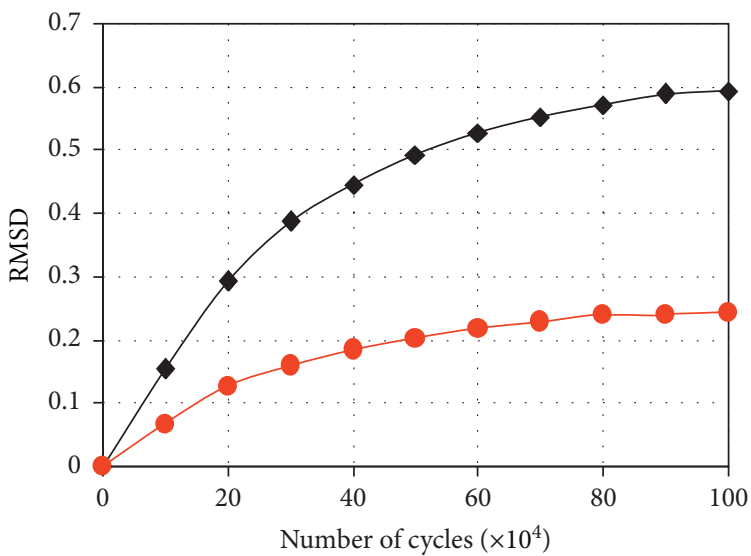

Calculated equation (3)

$\leadsto$ R-G

- R-B
Number of cycles $\left(\times 10^{4}\right)$
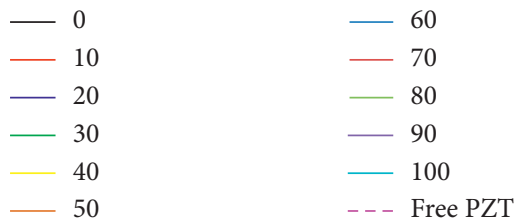

(b)

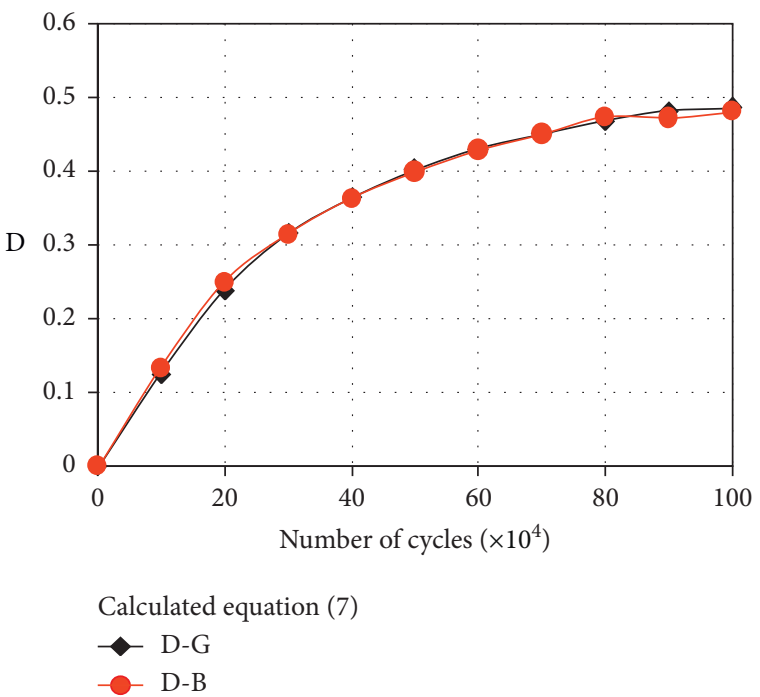

(d)

FIgURE 4: The signatures of specimen I15-1: (a) conductance G; (b) susceptance B; (c) RMSD calculated by equation (3) based on G and B signature (R-G and R-B), respectively; (d) D-G and D-B calculated by equation (7).

where $D_{r}$ is the magnitude of damage recovery of the specimen, $N$ is the number of cycles, and $y_{0}, A_{1}$, and $t_{1}$ are the parameters associated to initial damage.

At the same time, noticing that the fitting using the ExpDec1 formula needs to satisfy the condition of $\left.D_{r}\right|_{N=0}=0$, that is, $y_{0}+A_{1}=0$. So, equation (8) can be simplified as

$$
D_{r}=y_{0}\left[1-\exp \left(\frac{-N}{t_{1}}\right)\right] \text {. }
$$

The fitting results by equation (9) are also plotted in Figure 8 , and the fitting parameters and the initial damages $D_{0}$ calibrated in Section 4.3 are summarized in Table 5.

For equation (9), the parameter $y_{0}$ affects the final convergence value, while the parameter $t_{1}$ affects the evolution rate of the curve. Therefore, combined with what we have discussed in Section 3.1, there should be some kinds of relationships to be established between these two parameters 


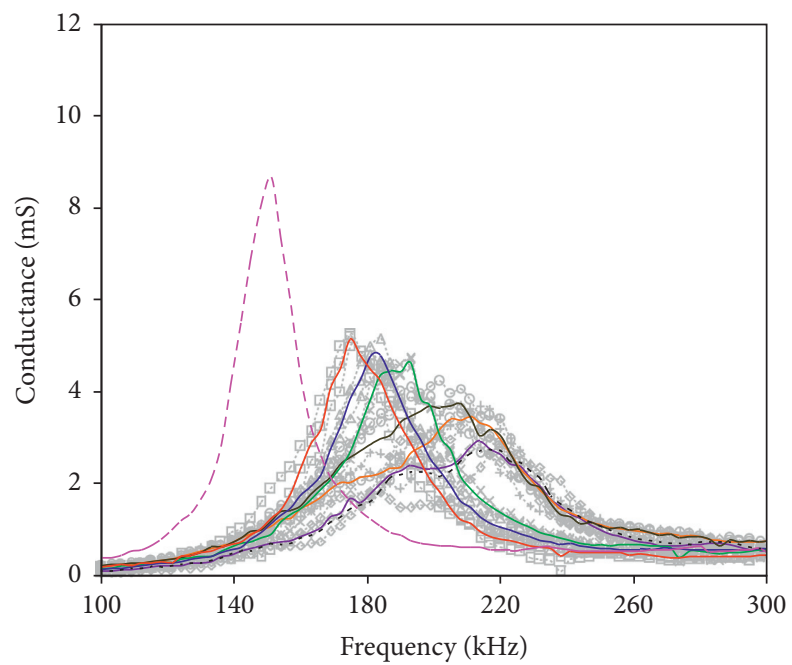

\begin{tabular}{|c|c|c|}
\hline$\ldots \quad \mathrm{I} 0-1$ & $\therefore \Delta \cdots$ & I12-2 \\
\hline I3-1 & ‥ & I15-2 \\
\hline . I6-1 & 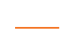 & Avg. of I3 \\
\hline$\times \quad$ I9-1 & 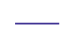 & Avg. of I12 \\
\hline A I12-1 &.... & Base line \\
\hline I15-1 & $\cdots \Delta$. & I0-3 \\
\hline Avg. of I0 & $\cdots+$ & I3-3 \\
\hline Avg. of I9 & ..o. & I6-3 \\
\hline - - - Free PZT & $\cdots x$. & I9-3 \\
\hline I0-2 & $\cdots \Delta$. & I12-3 \\
\hline I3-2 & ‥ & I15-3 \\
\hline I6-2 & 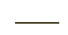 & Avg. of I6 \\
\hline I9-2 & - & Avg. of I15 \\
\hline
\end{tabular}

FIGURE 5: Influence of impact loading on the conductance signatures of PZT transducers.

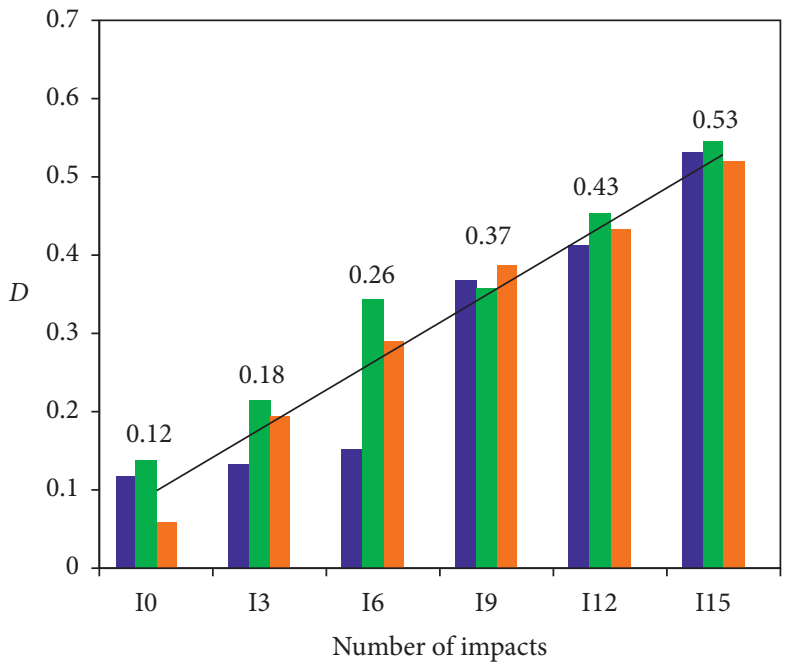

FIgURE 6: The calculation results of initial damage of each set of specimens.

$\left(y_{0}\right.$ and $\left.t_{1}\right)$ and the initial damage $\left(D_{0}\right)$, by which the parameter $D_{0}$ can be introduced into equation (9) if the following conditions (equations (10) and (11)) can be satisfied:

$$
\begin{gathered}
\left.D_{r}\right|_{D_{0} \longrightarrow 0^{+} \text {and } N=0}=0, \\
\left.D_{r}\right|_{D_{0} \longrightarrow 1^{-} \text {and } N>0}=1^{-},
\end{gathered}
$$




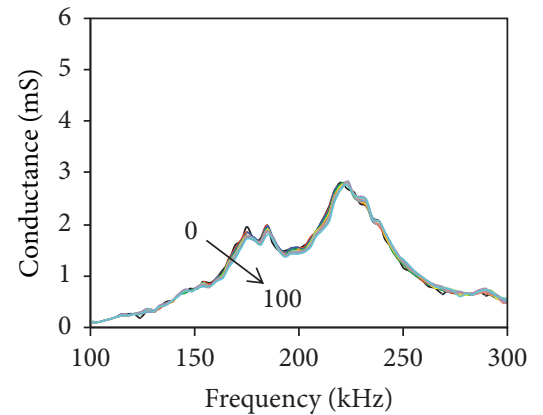

Number of cycles $\left(\times 10^{4}\right)$

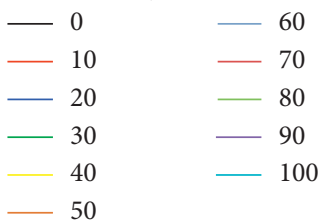

(a)

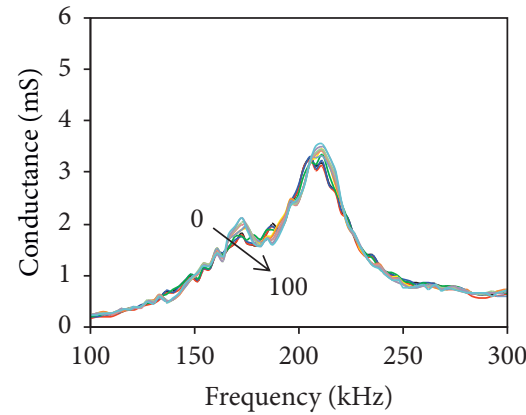

Number of cycles $\left(\times 10^{4}\right)$

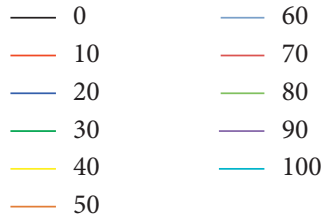

(d)

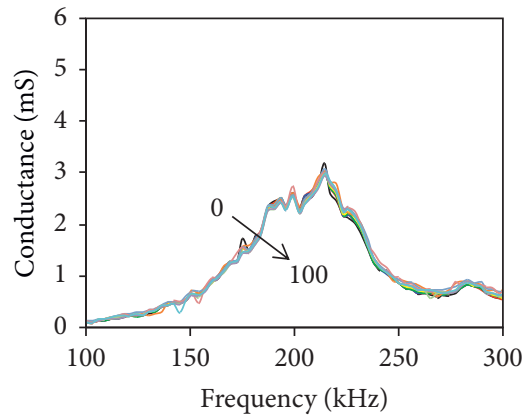

Number of cycles $\left(\times 10^{4}\right)$

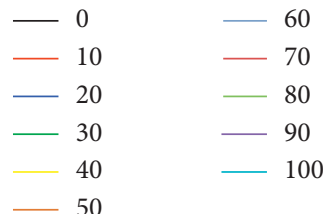

(b)

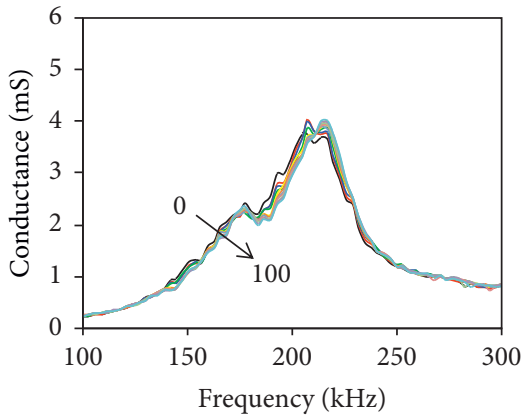

Number of cycles $\left(\times 10^{4}\right)$

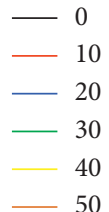

$-60$

$-70$

$-80$

$-90$

$-100$

(e)

(f)

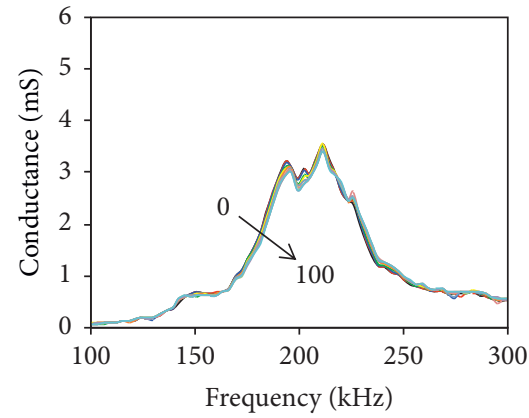

Number of cycles $\left(\times 10^{4}\right)$

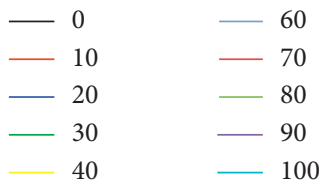

(c)

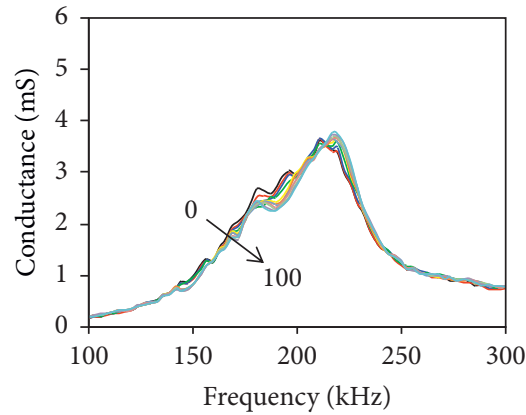

Number of cycles $\left(\times 10^{4}\right)$

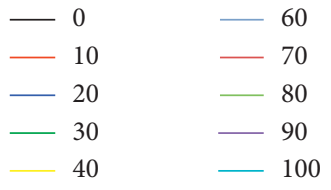

$-50$

Figure 7: Continued. 


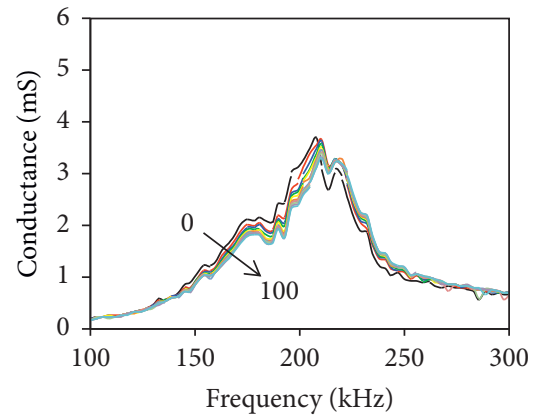

Number of cycles $\left(\times 10^{4}\right)$

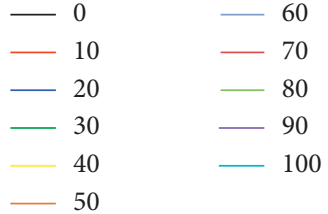

(g)

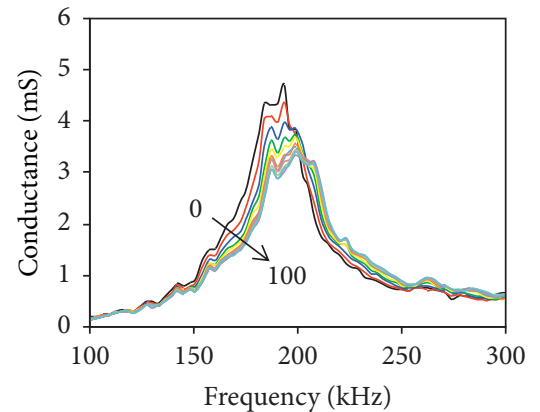

Number of cycles $\left(\times 10^{4}\right)$

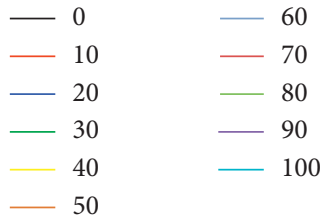

(j)

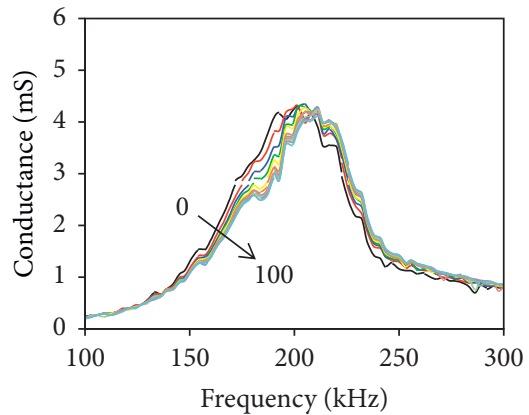

Number of cycles $\left(\times 10^{4}\right)$

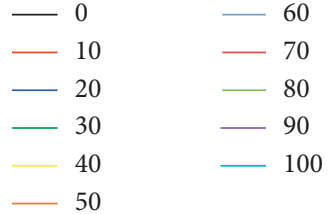

(h)

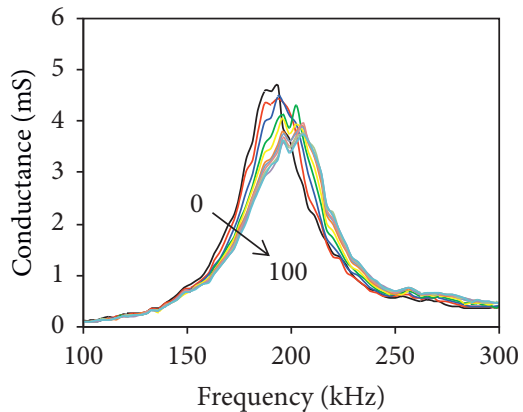

Number of cycles $\left(\times 10^{4}\right)$

$\begin{aligned}- & 0 \\ - & 10 \\ - & 20 \\ - & 30 \\ & 40 \\ - & 50\end{aligned}$

$-60$

$-70$

$-80$

- 90

- 100

(k)

Figure 7: Continued.

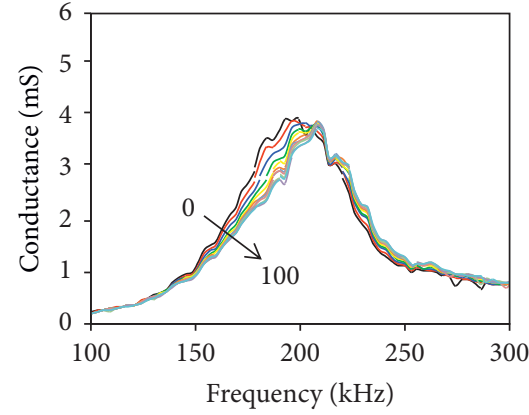

Number of cycles $\left(\times 10^{4}\right)$

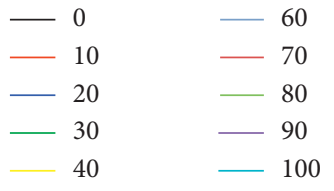

(i)

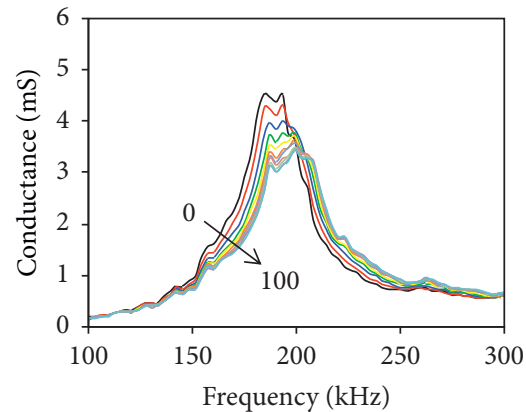

Number of cycles $\left(\times 10^{4}\right)$

$\begin{array}{ll}-0 & -60 \\ -10 & -70 \\ -20 & -80 \\ -30 & -90 \\ 40 & -100\end{array}$

(l) 


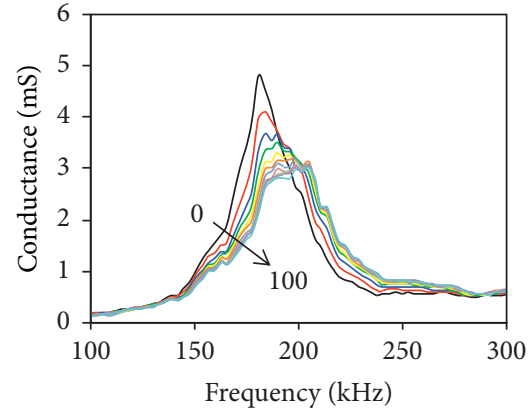

Number of cycles $\left(\times 10^{4}\right)$

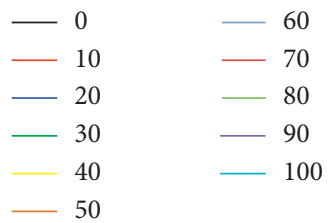

(m)

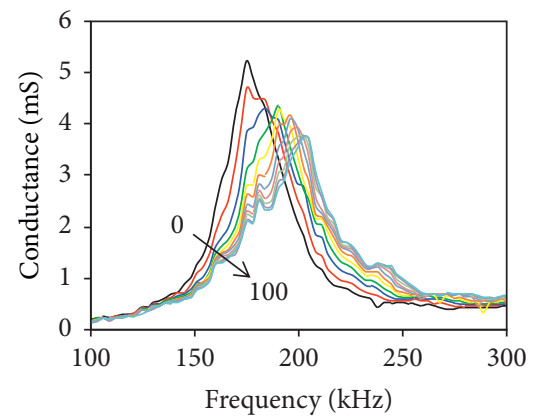

Number of cycles $\left(\times 10^{4}\right)$

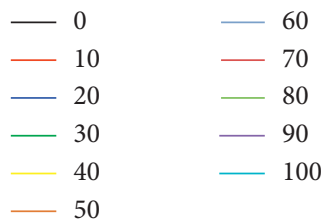

(p)

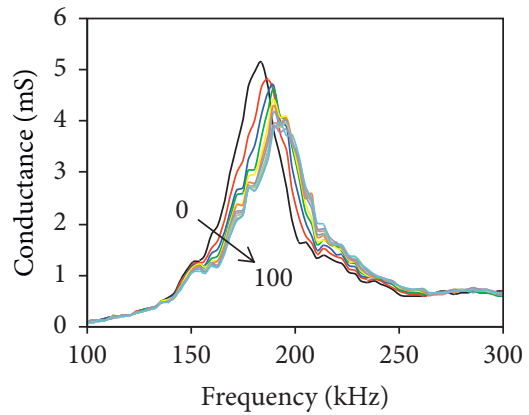

Number of cycles $\left(\times 10^{4}\right)$

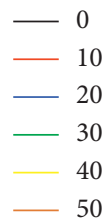

- 50

(n)

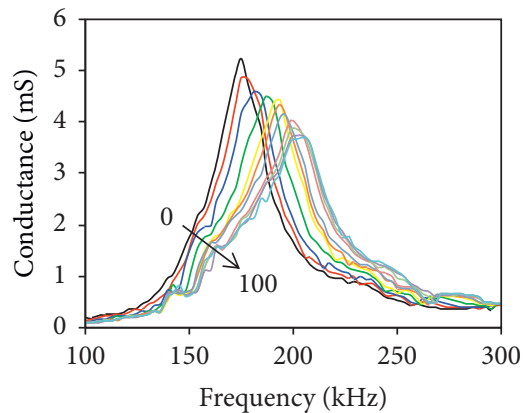

Number of cycles $\left(\times 10^{4}\right)$

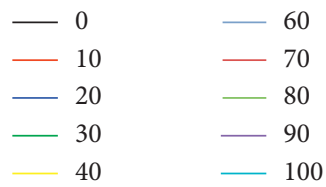

(q)

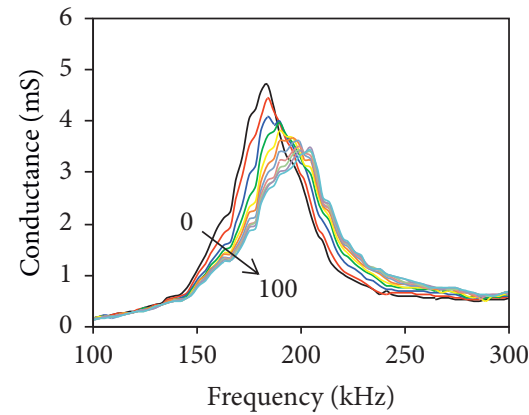

Number of cycles $\left(\times 10^{4}\right)$

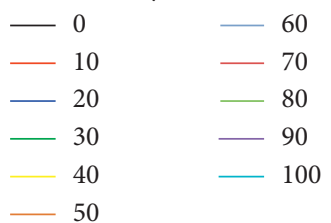

(o)

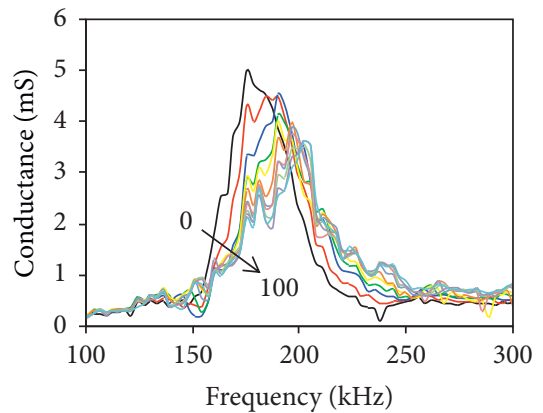

Number of cycles $\left(\times 10^{4}\right)$

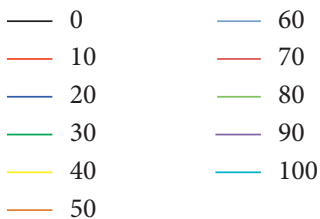

(r)

Figure 7: The conductance signatures generated during high cyclic loading for specimens with six different levels of initial damage. (a) I0-1. (b) I0-2. (c) I0-3. (d) I3-1. (e) I3-2. (f) I3-3. (g) I6-1. (h) I6-2. (i) I6-3. (j) I9-1. (k) I9-2. (l) I9-3. (m) I12-1. (n) I12-2. (o) I12-3. (p) I15-1. (q) I15-2. (r) I15-3.

where $D_{0} \longrightarrow 0^{+}$means it approaches to 0 positively, while $D_{0} \longrightarrow 1^{-}$means it approaches to 1 negatively.

After some regression analyses, the relationships between $y_{0}, t_{1}$, and $D_{0}$, respectively, were found and could be expressed as follows:

$$
\begin{aligned}
& y_{0}=a D_{0}^{b}, \\
& t_{1}=c\left(1-D_{0}\right) .
\end{aligned}
$$

By substituting equations (12) and (13) into equation (9), the evolution equation of damage index $\left(D_{r}\right)$ vs. cycle numbers $(N)$ considering the effect of initial damage $\left(D_{0}\right)$ is finally given as follows:

$$
D_{r}=a D_{0}^{b}\left\{1-\exp \left[-\frac{N}{c\left(1-D_{0}\right)}\right]\right\} .
$$

Using equations (12) and (13) to fit the data in Table 5, the parameters $a, b$, and $c$ are therefore determined as 1.385 , 1.664, and 47.876, respectively (see Figures 9 and 10).

The calculation result by equation (14) with $a=1.385$, $b=1.664$, and $c=47.876$ is shown in Figure 11. Agreement well with all the test data indicates that the proposed empirical expression is capable to predict the damage recovery behavior of initial damaged tunnel invert concrete under 

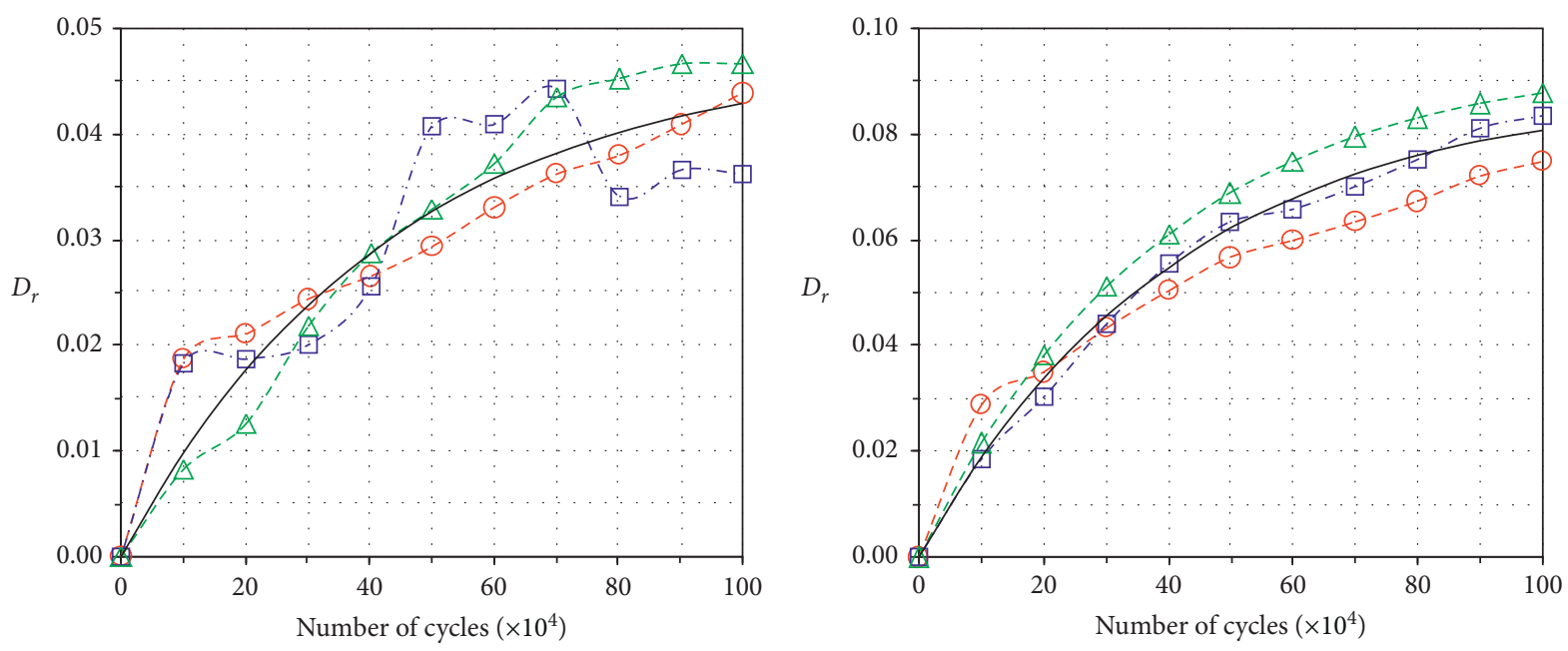

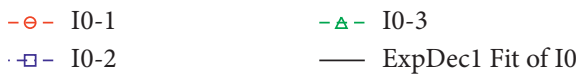

(a)

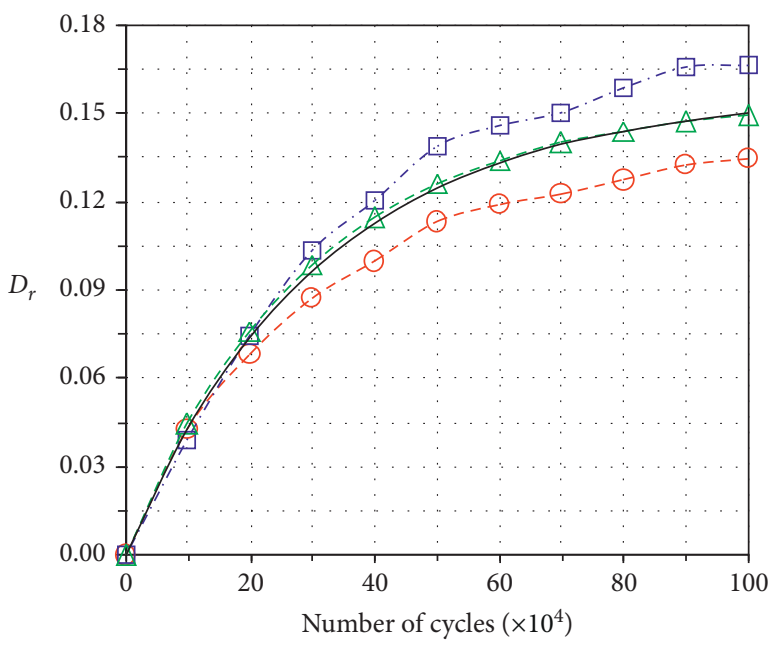

$\begin{array}{ll}-\ominus-\mathrm{I} 6-1 & -\Delta-\mathrm{I} 6-3 \\ -\square-\mathrm{I} 6-2 & - \text { ExpDec1 Fit of I6 }\end{array}$ $-\ominus-$ I3-1

$\square-\mathrm{I} 3-2$

-A- I3-3

_ ExpDec1 Fit of I3

(b)

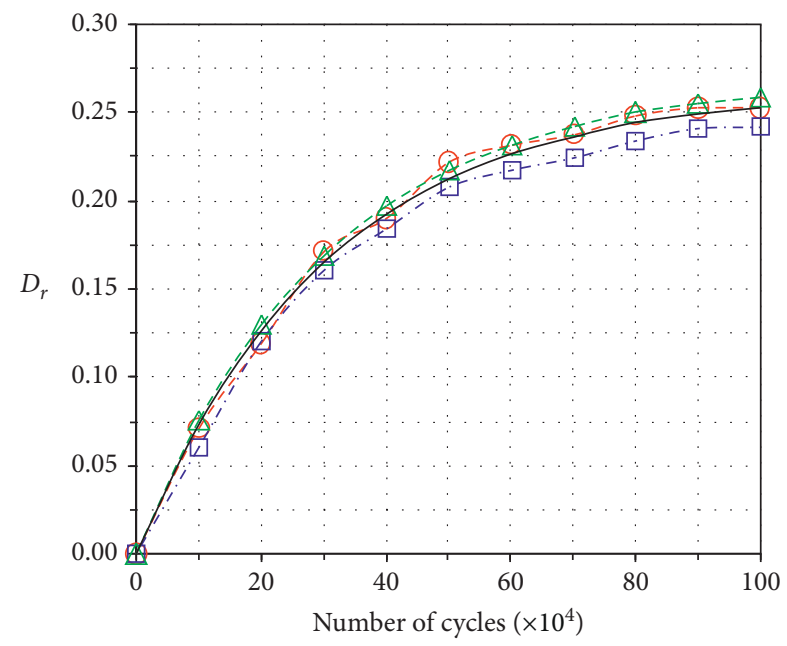

$-\ominus-\mathrm{I} 9-1$

$\square-19-2$

- $A-$ I9-3

_ ExpDec1 Fit of I9

(c)

(d)

Figure 8: Continued. 


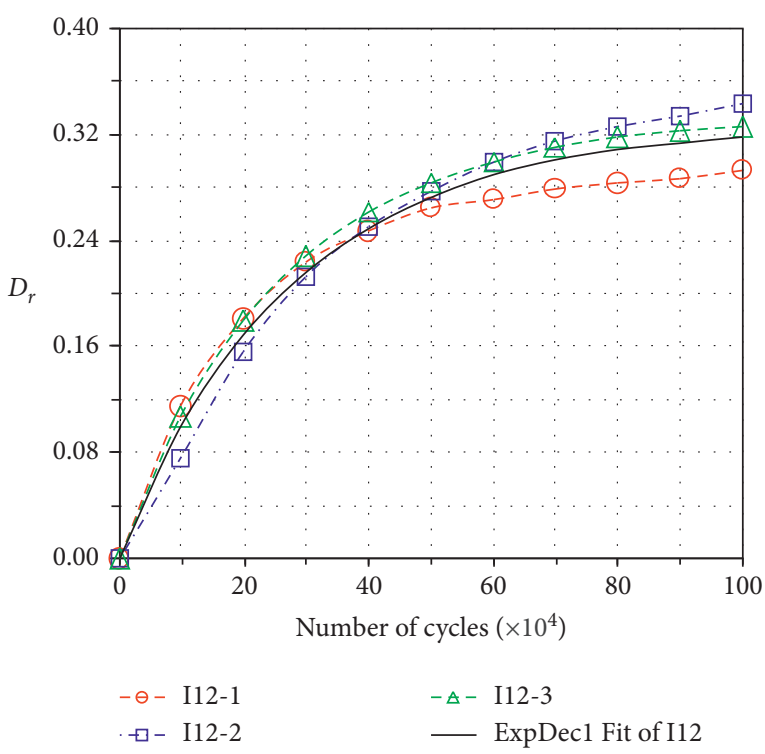

(e)

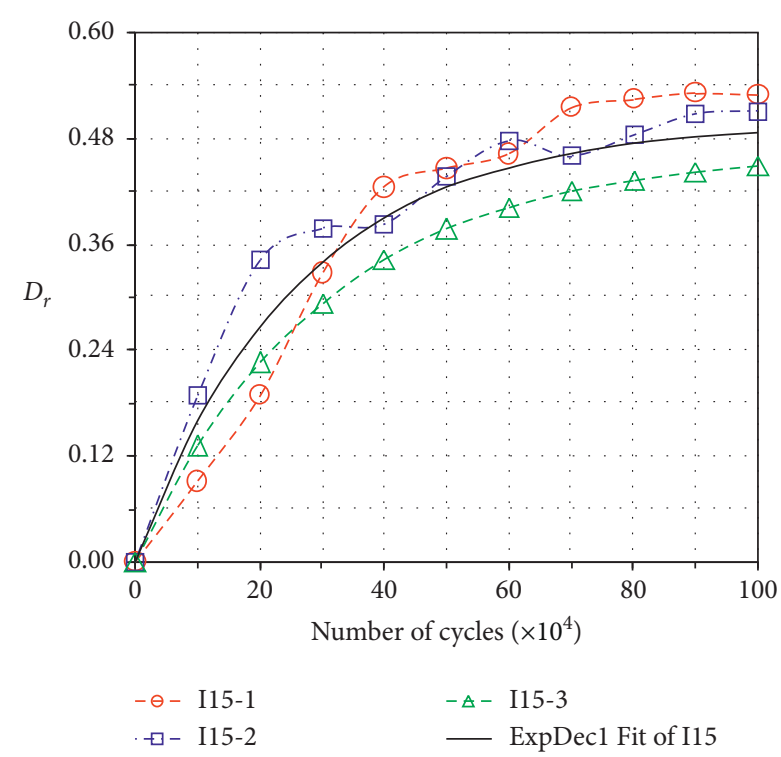

(f)

Figure 8: The damage evolution curves of initial damaged tunnel invert concretes subjected to high cyclic loading.

TABLE 5: Summary of fitting parameters of equation (9) and the initial damages quantified in Section 4.3.

\begin{tabular}{lcccccc}
\hline Parameters & I0 & I3 & I6 & I9 & I12 & I15 \\
\hline$Y_{0}$ & 0.0476 & 0.08862 & 0.15662 & 0.26283 & 0.32639 & 0.4951 \\
$T_{1}$ & 43.31712 & 41.31788 & 31.51705 & 30.36334 & 27.63689 & 25.81468 \\
$D_{0}$ & 0.11671 & 0.17979 & 0.26149 & 0.37002 & 0.43322 & 0.53184 \\
\hline
\end{tabular}

Notes. I0, I3, I6, I9, I12, and I15 are the specimen labels, representing specimens with $0,3,6,9,12$, and 15 numbers of impacts, respectively.

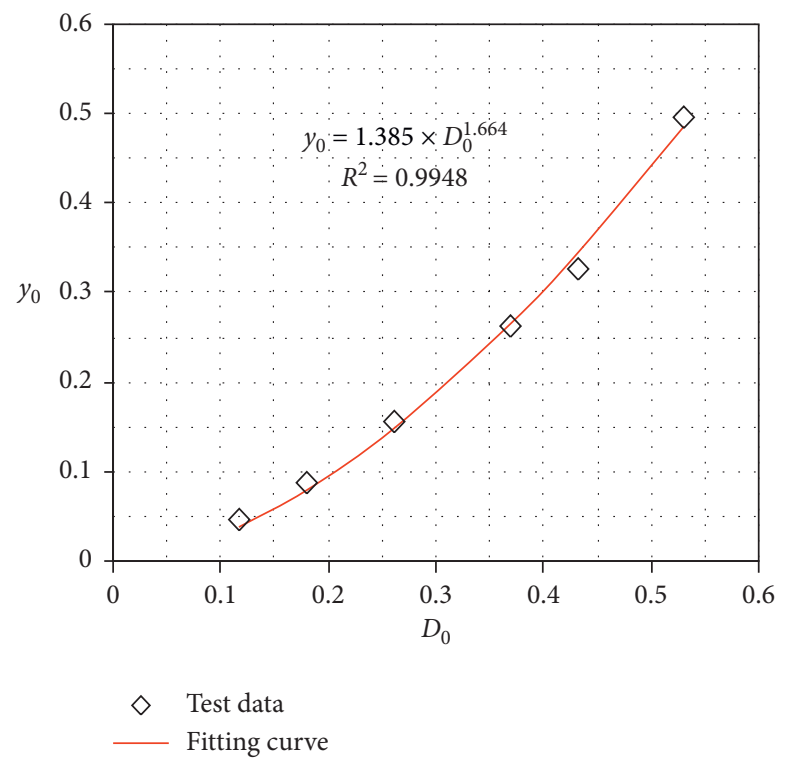

Figure 9: The relationship between $y_{0}$ and $D_{0}$.

high traffic cyclic loading. There should be noted that the calculation result by equation (14) as shown in Figure 11 is expected to be influenced by magnitude of cyclic loading and mechanical boundaries acting on the specimens, which were not considered in this study. A study by Liu et al. [29] showed that the high level of cyclic loading (up to $0.6 \sim 0.85$ of 


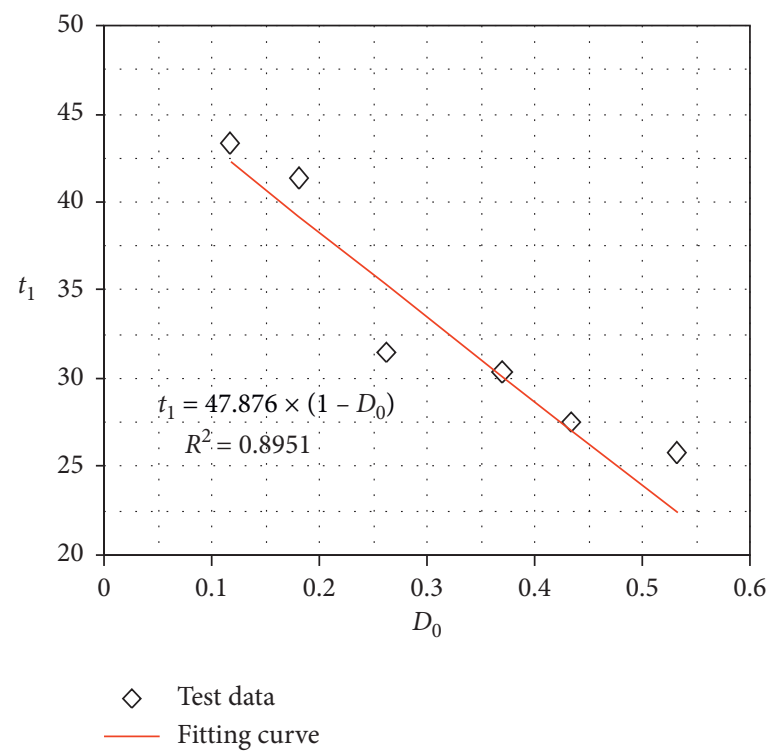

Figure 10: The relationship between $t_{1}$ and $D_{0}$.

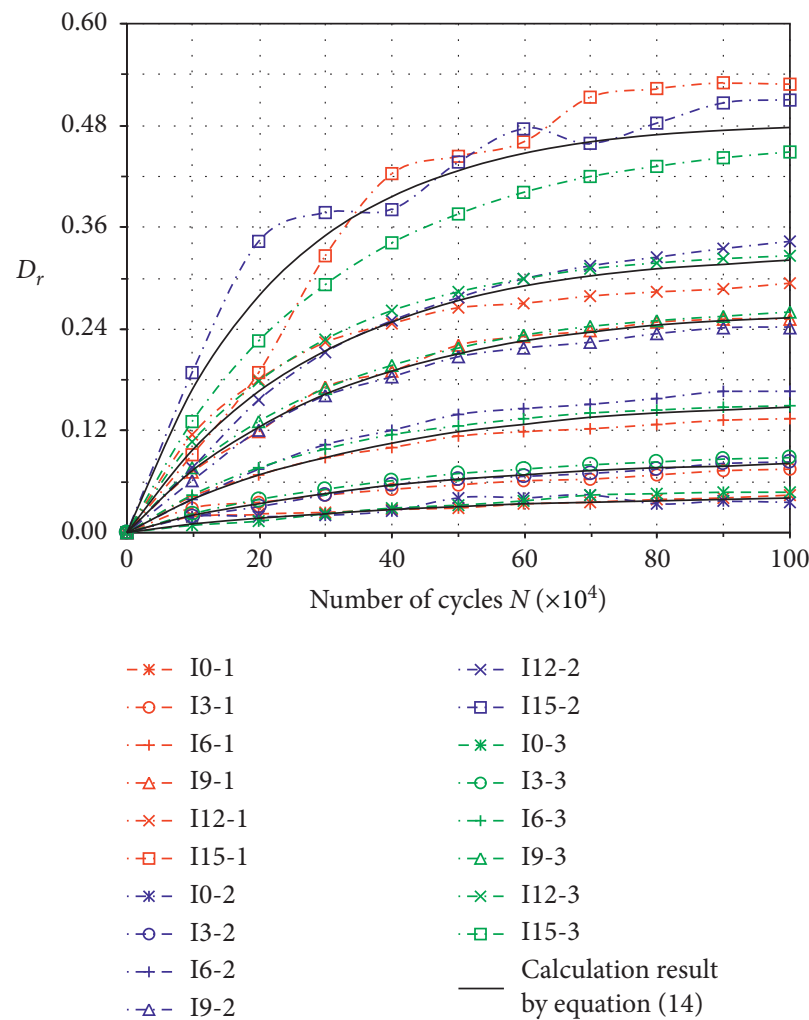

FIgURe 11: Comparison of calculated results and test data.

bending strength of concrete for static load $\sigma_{s}$ and $120 \sim 300 \mathrm{kPa}$ for dynamic load $\sigma_{d}$ ) can cause damage development to fatigue failure in tunnel invert concrete. Of course, such a loading level is much larger than that caused by the running train in real life, which may be the main reason for the different observations.

\section{Conclusions}

This paper addresses the major issue of experimental investigation of the damage evolution behavior of initial damaged tunnel invert concrete under high traffic cyclic loading. EMI technique was used as a main approach to 
quantify the damage level in specimens combined with a new damage index based on RMSD of conductance signature. The following conclusions can be drawn:

(1) The newly defined damage index is more advanced, which not only has a clearer physical significance than the traditional RMSD index but is not affected by signature selection. It has remarkable potential to make quantitative analysis for EMI technique.

(2) The damage of concrete specimen was validated which increases almost linearly with the number of impacts, suggesting that it is convenient and efficient to precast different levels of initial damage in the form of microcracks inside the concrete specimens.

(3) The high traffic cyclic loading acting on the tunnel invert concrete leads to the conductance signature rightward shifting with an increase in resonant frequency of the PZT-structure system, indicating that in general, the traffic cyclic loading is too small to make the microcracks propagate to fatigue failure in tunnel invert concrete, even if there is a large initial damage. On the contrary, with special mechanical boundaries, the local nominal stiffness of tunnel invert concrete will gradually increase with number of cycles, exhibiting a generalized damage recovery behavior.

(4) The initial damage of concrete has a significant influence on the generalized damage recovery behavior of tunnel invert concrete under cyclic loading. Such an effect can be well predicted by the proposed exponential empirical expression.

In future works, a series of cyclic loadings and mechanical boundaries will be conducted on tunnel invert concrete to investigate and establish a more general evolution equation from generalized damage recovery to damage development.

\section{Data Availability}

All the measured data and calculation result data used to support the findings of this study are available and included within the article.

\section{Conflicts of Interest}

The authors declare that they have no conflicts of interest.

\section{Acknowledgments}

The authors acknowledge the financial support of the National Natural Science Foundation of China (nos. 51508575 and U1734208), the Natural Science Foundation of Hunan Province, China (no. 2018JJ3657), and the National Defense Science and Technology Innovation Zone. The experimental work described in this paper was carried out in the National Engineering Laboratory for Construction Technology of the High Speed Railway in Central South University.

\section{References}

[1] N. Arun and S. Kolluru, "Experimental evaluation of loadinduced damage in concrete from distributed microcracks to localized cracking on electro-mechanical impedance response of bonded PZT," Construction and Building Materials, vol. 105, pp. 536-544, 2016.

[2] G. Park, H. Sohn, C. R. Farrar, and D. J. Inman, "Overview of piezoelectric impedance-based health monitoring and path forward," The Shock and Vibration Digest, vol. 35, no. 6, pp. 451-463, 2003.

[3] S. Bhalla and C. K. Soh, "High frequency piezoelectric signatures for diagnosis of seismic/blast induced structural damages," NDT \& E International, vol. 37, no. 1, pp. 23-33, 2004.

[4] S. Bhalla and C. K. Soh, "Structural health monitoring by piezo-impedance transducers. I: modeling," Journal of Aerospace Engineering, vol. 17, no. 4, pp. 154-165, 2004.

[5] C. K. Soh, K. K.-H. Tseng, S. Bhalla, and A. Gupta, "Performance of smart piezoceramic patches in health monitoring of a RC Bridge," Smart Materials and Structures, vol. 9, no. 4, pp. 533-542, 2000.

[6] C. Liang, F. P. Sun, and C. A. Rogers, "Coupled electromechanical analysis of adaptive material systems-determination of the actuator power consumption and system energy transfer," Journal of Intelligent Material Systems and Structures, vol. 5, no. 1, pp. 12-20, 1994.

[7] C. Liang, F. P. Sun, and C. A. Rogers, "Electro-mechanical impedance modeling of active material systems," Journal of Intelligent Material Systems and Structures, vol. 21, no. 3, pp. 232-252, 1994.

[8] Y. G. Xu and G. R. Liu, "A modified electro-mechanical impedance model of piezoelectric actuator-sensors for debonding detection of composite patches," Journal of Intelligent Material Systems and Structures, vol. 13, no. 6, pp. 389-396, 2002.

[9] S.-W. Zhou, C. Liang, and C. A. Rogers, "An impedance-based system modeling approach for induced strain actuator-driven structures," Journal of Vibration and Acoustics, vol. 118, no. 3, pp. 323-331, 1996.

[10] F. P. Sun, Z. Chaudhry, C. Liang, and C. A. Rogers, "Truss structure integrity identification using PZT sensor-actuator," Journal of Intelligent Material Systems and Structures, vol. 6, no. 1, pp. 134-139, 1995.

[11] G. Park, H. H. Cudney, and D. J. Inman, "Impedance-based health monitoring of civil structural components," Journal of Infrastructure Systems, vol. 6, no. 4, pp. 153-160, 2000.

[12] Y. Yang and Y. Hu, "Electromechanical impedance modeling of PZT transducers for health monitoring of cylindrical shell structures," Smart Materials and Structures, vol. 17, Article ID 015005, 2007.

[13] S. Yan, W. Sun, G. Song et al., "Health monitoring of reinforced concrete shear walls using smart aggregates," Smart Materials and Structures, vol. 18, pp. 3149-3160, 2009.

[14] G. Park, H. H. Cudney, and D. J. Inman, "Feasibility of using impedance-based damage assessment for pipeline structures," Earthquake Engineering \& Structural Dynamics, vol. 30, no. 10, pp. 1463-1474, 2001.

[15] X. Qing, W. Li, Y. Wang, and H. Sun, "Piezoelectric transducer-based structural health monitoring for aircraft applications," Sensors, vol. 19, no. 3, p. 545, 2019.

[16] Z. Wang, D. Chen, L. Zheng, L. Huo, and G. Song, "Influence of axial load on electromechanical impedance (EMI) of embedded piezoceramic transducers in steel fiber 
concretefluence of axial load on electromechanical impedance (EMI) of embedded piezoceramic transducers in steel fiber concrete," Sensors, vol. 18, no. 6, Article ID 1782, 2018.

[17] L. S. Huo, D. D. Chen, Y. B. Liang et al., "Impedance based bolt pre-load monitoring using piezoceramic smart washer," Smart Materials and Structures, vol. 26, Article ID 057004, 2017.

[18] B. Wang, L. Huo, D. Chen, W. Li, and G. Song, "Impedancebased pre-stress monitoring of rock bolts using a piezoceramic-based smart washer-a feasibility study," Sensors, vol. 17, no. 2, p. 250, 2017.

[19] D. Ai, H. Luo, C. Wang, and H. Zhu, "Monitoring of the loadinduced RC beam structural tension/compression stress and damage using piezoelectric transducers," Engineering Structures, vol. 154, pp. 38-51, 2018.

[20] V. G. M. Annamdas, Y. Yang, and C. K. Soh, "Influence of loading on the electromechanical admittance of piezoceramic transducers," Smart Materials and Structures, vol. 16, no. 5, pp. 1888-1897, 2007.

[21] D. Ai, H. Zhu, and H. Luo, "Sensitivity of embedded active PZT sensor for concrete structural impact damage detection," Construction and Building Materials, vol. 111, pp. 348-357, 2016.

[22] A. Dixit and S. Bhalla, "Prognosis of fatigue and impact induced damage in concrete using embedded piezo-transducers," Sensors and Actuators A: Physical, vol. 274, pp. 116-131, 2018.

[23] D. Ai, H. Zhu, H. Luo, and C. Wang, "Mechanical impedance based embedded piezoelectric transducer for reinforced concrete structural impact damage detection: a comparative study," Construction and Building Materials, vol. 165, pp. 472-483, 2018.

[24] B. Qi, Q. Kong, H. Qian et al., "Study of impact damage in PVA-ECC beam under low-velocity impact loading using piezoceramic transducers and PVDF thin-film transducers," Sensors, vol. 18, no. 3, p. 671, 2018.

[25] S. Fan, S. Zhao, B. Qi, and Q. Kong, "Damage evaluation of concrete column under impact load using a piezoelectricbased EMI technique," Sensors, vol. 18, no. 5, p. 1591, 2018.

[26] C. K. Soh and S. Bhalla, "Calibration of piezo-impedance transducers for strength prediction and damage assessment of concrete," Smart Materials and Structures, vol. 14, no. 4, pp. 671-684, 2005.

[27] M. Jin, L. Jiang, M. Lu, N. Xu, and Q. Zhu, "Characterization of internal damage of concrete subjected to freeze-thaw cycles by electrochemical impedance spectroscopy," Construction and Building Materials, vol. 152, pp. 702-707, 2017.

[28] Y. Y. Lim and C. K. Soh, "Fatigue life estimation of a 1D aluminum beam under mode-I loading using the electromechanical impedance technique," Smart Materials and Structures, vol. 20, no. 12, Article ID 125001, 2011.

[29] N. Liu, L. Peng, C. Shi, and M. Lei, "Experimental and model study on dynamic behaviour and fatigue damage of tunnel invert," Construction and Building Materials, vol. 126, pp. 777-784, 2016.

[30] C. K. Soh and Y. Y. Lim, "Detection and characterization of fatigue induced damage using electromechanical impedance technique," Advanced Materials Research, vol. 79-82, pp. 2031-2034, 2009.

[31] Y. Y. Lim and C. K. Soh, "Estimation of fatigue life using electromechanical impedance technique," Proceedings of SPIE, vol. 7647, pp. 764722-764731, 2010.

[32] S. Bhalla and N. Kaur, "Prognosis of low-strain fatigue induced damage in reinforced concrete structures using embedded piezo-transducesrs," International Journal of $\mathrm{Fa}$ tigue, vol. 113, pp. 92-112, 2018.

[33] J. Li, Z. Luo, L. Lin, X. Li, and M. Lei, "Quantitative health monitoring of fatigue crack initiation and propagation in aluminium specimen based on electromechanical impedance technique," Insight-Non-destructive Testing and Condition Monitoring, vol. 54, no. 5, pp. 267-271, 2012.

[34] M. Haq, S. Bhalla, and T. Naqvi, "Fatigue damage monitoring of reinforced concrete frames using wavelet transform energy of PZT-based admittance signals," Measurement, vol. 164, Article ID 108033, 2020.

[35] S. Bhalla, Y. W. Yang, J. Zhao, and C. K. Soh, "Structural health monitoring of underground facilities-technological issues and challenges," Tunnelling and Underground Space Technology, vol. 20, no. 5, pp. 487-500, 2005.

[36] A. C. Rutherford, G. Park, and C. R. Farrar, "Non-linear feature identifications based on self-sensing impedance measurements for structural health assessment," Mechanical Systems and Signal Processing, vol. 21, no. 1, pp. 322-333, 2007.

[37] R. K. Abu Al-Rub and S.-M. Kim, "Computational applications of a coupled plasticity-damage constitutive model for simulating plain concrete fracture," Engineering Fracture Mechanics, vol. 77, no. 10, pp. 1577-1603, 2010.

[38] Z. D. Ding, "Dynamic properties of soft rock and the safety of base structure of high-speed railway tunnels," Doctoral Dissertation, Central South University, Changsha, China, 2012.

[39] P. Liu, W. Wang, Y. Chen, X. Feng, and L. Miao, "Concrete damage diagnosis using electromechanical impedance technique," Construction and Building Materials, vol. 136, pp. 450-455, 2017.

[40] F. P. Sun, Z. Chaudry, C. A. Rogers, M. Majmundar, and C. Liang, "Automated real-time structure health monitoring via signature pattern recognition," Smart Structures and Materials: Smart Structures and Integrated Systems, vol. 2443, pp. 236-247, 1995.

[41] Y. Yang, Y. Hu, and Y. Lu, "Sensitivity of PZT impedance sensors for damage detection of concrete structures," Sensors, vol. 8, no. 1, pp. 327-346, 2008.

[42] Y. Yang, H. Liu, V. G. M. Annamdas, and C. K. Soh, "Monitoring damage propagation using PZT impedance transducers," Smart Materials and Structures, vol. 18, no. 4, Article ID 045003, 2009.

[43] W. J. Li, S. L. Fan, S. C. M. Ho et al., "Interfacial debonding detection in fiber-reinforced polymer rebar-reinforced concrete using electro-mechanical impedance technique," Structural Health Monitoring, vol. 17, no. 3, pp. 1-11, 2017.

[44] P. Negi, T. Chakraborty, N. Kaur, and S. Bhalla, "Investigations on effectiveness of embedded PZT patches at varying orientations for monitoring concrete hydration using EMI technique," Construction and Building Materials, vol. 169, pp. 489-498, 2018.

[45] S. W. Shin and T. K. Oh, "Application of electro-mechanical impedance sensing technique for online monitoring of strength development in concrete using smart PZT patches," Construction and Building Materials, vol. 23, no. 2, pp. 1185-1188, 2009.

[46] R. Taiie and H. K. Lee, "Monitoring the strength development in concrete by EMI sensing technique," Construction and Building Materials, vol. 24, no. 9, pp. 1746-1753, 2010.

[47] D. Wang and H. Zhu, "Monitoring of the strength gain of concrete using embedded PZT impedance transducer," 
Construction and Building Materials, vol. 25, no. 9, pp. 3703-3708, 2011.

[48] Y. Y. Lim, K. Z. Kwong, W. Y. H. Liew, and C. K. Soh, "Nondestructive concrete strength evaluation using smart piezoelectric transducer-a comparative study," Smart Materials and Structures, vol. 25, no. 8, Article ID 085021, 2016. 